\title{
A INFÂNCIA DA LITERATURA: EXERCÍCIOS DO OLHAR ${ }^{\mathrm{i}}$
}

\author{
Marina Miranda Fiuza \\ Doutoranda em Literatura e Crítica Literária pela Pontifícia Universidade Católica de São \\ Paulo (PUC-SP) \\ marinafiuza@yahoo.com.br
}

\section{RESUMO}

A partir da análise da obra infantojuvenil O olho de vidro do meu avô (2004) do escritor mineiro Bartolomeu Campos de Queirós (1944-2012), o presente artigo busca construir relações de equivalência entre a infância e a literatura, possibilitadas, ao nosso ver, pela metáfora do "olho de vidro". Adotando um viés exploratório da filosofia fenomenológica buscaremos lançar luzes para uma leitura adensada do literário do título em questão em seu aspecto metalinguístico.

Palavras-chave: fenomenologia do olhar, infância, literatura infantojuvenil.

\section{ABSTRACT}

Through the analysis of the book "O olho de vidro do meu avô" (2004) by Bartolomeu Campos de Queirós (19442012), this article aims to articulate the concepts of childhood and literature. This is made possible, I argue, by the metaphor of the "glass eye". Adopting a phenomenological standpoint, I intend to establish an in-depth literary approach of the given book in its metalinguistic aspect.

Keywords: phenomenology, childhood, children's literature. 
Bartolomeu Campos de Queirós (1944-2012) publicou seu primeiro livroii em 1974.

Desde então, ficou evidente que a prosa poética do autor é comprometida ora com a educação, ora com a política, e sempre com a linguagem. Basta ver a constante atividade do autor em projetos sociais ou ouvir uma de suas palestras para perceber que se trata de um homem amplamente consciente em seu ofício de escritor.

Apesar de negar a produção literária dividida em segmentos, Bartolomeu concentra a maioria de suas publicações na categoria infantojuvenil. Ao contrário do que se poderia pensar, a escrita de Bartolomeu se revigora diante do leitor mirim e, apesar do texto simples, expressa-se como objeto pretensioso e de forte teor literário. Tal habilidade do escritor rendeu-Ihe inúmeros prêmios nacionais e internacionais durante sua profícua obra, que conta com mais de quarenta publicações. Em 2010, Bartolomeu Campos de Queirós tornou-se membro da Academia Mineira de Letras. Em seu discurso de posse, reafirmou a ideia, já expressa em outras ocasiões, de que a literatura não tem destinatário fixo e estabeleceu aquele que deveria ser o único vínculo entre sua obra e a infância:

Passei a perceber a proximidade da infância com a literatura. Pude compreender um conceito de Jung 'Nascemos originais e morremos cópias'. A capacidade da criança de não se surpreender com o nonsense me levava a mais fantasias. E tudo na percepção infantil possui uma linguagem: plantas, água, vento, flor, pedra, tudo podia ser escutado. A linguagem não se ausentava de nada. Daí minha proposição de configurar uma literatura capaz de permitir a leitura também dos mais jovens, e ressuscitar a infância que sobrevive nos adultos (QUEIRÓS, 2010, p. 34).

O nonsense de que fala o escritor poderia ser compreendido como sendo tudo aquilo que causa espanto a um adulto, para quem a ideia do normal já foi calcificada 
pelas convenções sociais e, mais especificamente no caso da literatura, pelas convenções da língua. A criança, justamente por não ter internalizado a língua como um conjunto de normas e por ser desprovida de uma experiência elaborada do mundo, estaria, desta forma, mais aberta para as estripulias do texto literário. Uma vez que não está atrelada ao código da língua, a percepção infantil faz com que não só texto, mas tudo o que há no mundo, lhe comunique algo.

Assim, ao propor um retorno à infância, Bartolomeu não pretende suscitar recordações factuais biográficas que provoquem identificação entre autor e leitor, como poderia ser interpretada sua fala diante do caráter memorialista de grande parte de sua obra. Mais do que isso, Bartolomeu propõe um retorno à percepção infantil, cujos ouvidos estão receptivos e atentos à voz do mundo. Ou ainda, tomando emprestadas as palavras do filósofo Merleau-Ponty, o que sugere Bartolomeu é reaprender a ver o mundo.

Dentre as obras do autor, elegemos $O$ olho de vidro do meu avô, publicada em 2004 pela editora Moderna, vencedora de importantes prêmios como o Prêmio Altamente Recomendável e Prêmio O melhor para o Jovem, "Hors Concours", FNLIJ 2004, além do Prêmio Nestlé de Literatura e do Jabuti, ambos em 2005.

Trata-se de uma narrativa em prosa poética, cujo enredo consiste nas lembranças da infância de um narrador-personagem, as quais se concentram na figura do avô e nos mistérios sugeridos por seu olho de vidro.

O narrador - personagem, agora, adulto - não relembra o passado como algo distante e fixo. O passado bem como as angústias e medos vividos no período de infância são trazidos para o presente pelo vagão da lembrança. As emoções de outrora não são apenas rememoradas com a distância do olhar adulto, mas revividas pelo narrador no 
presente. Poderíamos dizer que tais memórias não narram o passado, mas um presente que foi. É o passado tornando-se presente pela lembrança.

Mais do que um livro de memórias, porém, percebemos no texto $O$ olho de vidro do meu avô um forte teor metalinguístico. Ao discorrer sobre a forma peculiar com que o avô percebia o mundo, o narrador também percorre os caminhos da filosofia ontológica e da própria literatura.

A narrativa em questão se inicia com a apresentação do avô por meio daquela que era sua mais marcante característica: o olho de vidro. O que era capaz de ver aquele olho? Quais angústias teria o avô possuindo apenas "meia-visão" do mundo? Como ele, neto, era visto pelo "meio-olhar" do avô? Diante de indagações, a imagem do avô vai se construindo no decorrer da narrativa, baseada nas suspeitas do neto mais do que em fatos vividos e relatados.

A relação entre o avô e o neto, pela visão deste último, era de íntima cumplicidade, compartilhada no silêncio das tardes na casa do interior de Minas Gerais. Ao observar o avô, era sempre o olho de vidro que lhe causava maior curiosidade. Qual visão poderia ter aquele homem cujo par de olhos era constituído por um olho de verdade e outro de mentira? Tal questão perturbava-o de tal forma que o "meio-olhar" do avô passa a constituir a própria maneira de olhar do neto, que irá elaborar uma narrativa a partir dos pilares do olho da verdade e do olho da mentira. É o narrador quem passa a descrever o que a visão de olho de vidro é capaz de ver.

Logo no primeiro parágrafo podemos identificar alguns duplos de opostos.

Era de vidro o seu olho esquerdo. De vidro azul-claro e parecia envernizado por uma eterna noite. Meu avô via a vida pela metade, eu cismava, sem fazer meias perguntas. Tudo para ele se resumia em um 
meio-mundo. Mas via a vida por inteiro, eu sabia. Seu olhar, muitas vezes, era parado como se tudo estivesse num mesmo ponto. E estava. Ele nos doava um sorriso leve com meio canto da boca, como se zombando de nós. O pensamento vê o mundo melhor que os olhos, eu tentava justificar. O pensamento atravessa as cascas e alcança o miolo das coisas. Os olhos só acariciam as superfícies. Quem toca o bem dentro de nós é a imaginação (QUEIRÓS, 2004, p. 5).

Claro e noite. Metade e inteiro. Cascas e miolo. Dualidades representadas pelo par de olhos do avô transparecem na visão de um mundo também dividido entre opostos. "Tudo no mundo é, em parte, uma verdade e, por outra parte, uma mentira" (QUEIRÓS, 2004, p. 7), afirma o narrador. Enquanto o olho sadio do avô enxergava os visíveis do mundo, o olho fictício era capaz de contemplar seus invisíveis. Desprovido da habilidade de ver, ao olho de vidro restava a opção de fantasiar. Por não ficar presa aos contornos do visível do mundo, a visão do olho de vidro se ampliava para além dos horizontes.

Observemos o parágrafo a seguir, no qual a ideia da potência do olho de vidro é reforçada:

Eu achava que tudo era imaginação de meu avô, mas continuava com medo. É que ele tinha um olhar frio e outro quente. Tinha um olho que via e outro que só desejava. (...) Sempre achei que meu avô enxergava mais com o olho da mentira que com o olho da verdade. Com o olho do desejo ele inventava. Com o olho da verdade ele só via o que já existia. Com olho frio a gente vê assombração e com olho quente só o que nos assombra (QUEIRÓS, 2004, p. 37).

Notamos, assim, a cisão entre dois tipos de olhar: um primeiro, representado pelo olho de verdade, e um outro representado pelo olho da mentira. Ao primeiro olhar, poder-se-ia atribuir um aspecto de passividade, visto que o olho da verdade capta tudo aquilo que se posiciona dentro de seu campo visual. Basta estar diante do olho da verdade para ser percebido por ele. Porém, tal visão se limita aos contornos dos objetos, 
às suas superfícies. Contrariamente, o olho da mentira, por ser fictício, é cego. Persistindo em sua tarefa de ver, porém, abre-se para um tipo de visão ativa, a qual requer um esforço criativo por parte daquele que deseja ver. Por não estar preso às superfícies do visível, o olhar de mentira extrapola os limites do campo visual, atravessa as cascas buscando penetrar no miolo das coisas.

O par de olhos formado pelo olho da verdade e o da mentira opera em conjunto e complementação. É importante destacar que o avô era cego apenas de um olho e que sua visão era, portanto, apenas parcialmente limitada. Ao afirmar que o avô via melhor com o olho da mentira, o narrador não exclui a importância do olho da verdade. É entre a verdade e a mentira, entre a passividade e a atividade, entre as superfícies e os miolos, entre os visíveis e os invisíveis que a visão do avô se potencializa, uma vez que se torna capaz de captar o mundo por inteiro, em seus direitos e avessos.

Enquanto um olhar totalmente cego não teria ponto de partida para imaginar, o olhar completamente sadio se resumiria a ver apenas o que lhe é posto. Dotado de dois olhos da verdade, o mundo apareceria diante do ser vidente independentemente da vontade deste de ver ou não. Aos olhos da verdade tudo seria passível de ser percebido; tratar-se-ia de uma atividade involuntária e automática.

O narrador, contagiado pela duplicidade da visão do avô, passa a não se contentar com a visão de seus dois olhos da verdade, desconfiando do mundo visível apenas à vol d'oiseau. "Ninguém esgota o mundo com o olhar, mesmo possuindo dois olhos sem vidro. Mas a gente, com dois olhos, sempre olha e não acredita no que vê" (QUEIRÓS, 2004, p. 8). A visão convencional de dois olhos sadios permite a visão de um mundo também consolidado, onde prevalece a representação e o reconhecimento à apresentação e o conhecimento. 
Observamos, assim, que o olho de vidro tem forte teor metafórico dentro da narrativa. Ao escrever sobre a visão do avô, o narrador não só propõe como também adota, ele mesmo, um olhar com olho de vidro. Podemos estabelecer, neste momento, uma relação clara do "olhar de vidro" com o "olhar fenomenológico" característico do literário, o qual propõe uma restauração da percepção ao fértil território da experiência perceptual. A essa experiência é exigida o desapego de quaisquer pré-informações que o mundo possa apresentar diante do homem já experiente. Exige-se, digamos, uma varredura de tudo aquilo que se constrói a partir da experiência primária: significações, conceitos, funcionalidades, determinações. Só com os olhos despidos de todo esse aparato é possível provar o mundo de fato. A verdade do mundo só vem à luz na medida em que os olhos se tornam cegos para as convenções do conhecimento.

O olho de vidro, apesar de apresentar perfeita semelhança com o olho natural, é desprovido da função de ver. Temos, assim, um suposto órgão de visão que, apesar das aparências e do contexto onde se apresenta - num par de olhos -, não exerce sua atividade primordial, que é a visão. Podemos dizer que o olho de vidro desestabiliza a visão, ao operar, ainda que inutilmente, ao lado de um olho sadio. Assim, a visão dual estabelecida pela coexistência entre um olho sadio e outro cego passa a ser um exercício de humanidade para este narrador na medida em que propõe uma visão real das coisas, não se limitando às funcionalidades e conceitos a elas atribuídos, mas alcançando também aquilo que as torna existência latente e carnal. "Como meu avô, eu via o visível e me encantava com o invisível. Não ter um olho é ver duas vezes. Com um olho você vê o raso e com o outro mergulha o fundo" (QUEIRÓS, 2004, p. 12). Recorrendo ao vocabulário da fenomenologia merleau-pontyana, o narrador nos aponta para um tipo de visão capaz 
de entrelaçar os visíveis e invisíveis das coisas, fazendo saltar desse quiasma a carne do mundo (Cf. MERLEAU-PONTY, 2009, p. 129-130).

Dessa forma, ver o mundo com um olho de vidro e um olho sadio não é sobrevoálo apenas, observando as superfícies e reconhecendo-as, como frequentemente ocorre quando se tem dois olhos da verdade. Ver o mundo exige ter um olho de vidro, o qual nos torna cegos para todos os pré-conceitos que fazem das coisas símbolos, para que possam, então, serem percebidas como ícones pelo olho da verdade. Não seria esse também o procedimento da metáfora? É preciso cegar o conceito referencial para que a palavra ganhe força como ícone e imagem.

No contexto de nossa interpretação, a "superfície" do mundo, a que se refere o narrador com frequência, não compreende apenas à visualidade do mundo, ou ainda, ao mundo aparente. Mais que isso, ao dizer que o olhar sadio alcança a superfície do mundo, o narrador já embute nessa metáfora uma crítica ao modus vivendi do homem contemporâneo. Inserido em uma dinâmica de vida acelerada, com valores capitalistas e absolutamente sobrecarregada de informações, é pouco provável que ao homem sobre a oportunidade de sentir o mundo em sua essência, em sua carnalidade. Na inércia da vida prática, esse homem toca, apenas superficialmente, o mundo pelo olhar. O miolo das coisas, assim, representaria uma verdade soterrada pela dinâmica do dia a dia. É preciso um esforço de escavação para chegar à coisa em si e, finalmente, experimentá-la sensitivamente. É preciso cegar-se para um mundo superficial, silenciar a voz de um mundo prático para permitir que as coisas se mostrem e exponham sua essência.

O silêncio é essência. Se o olho do meu avô via, era uma visão em silêncio. Envolvido pelo silêncio, meu avô dispensava os olhos. Abaixava 
as pálpebras e buscava outras lonjuras. O silêncio era seu bilhete para viagens (QUEIRÓS, 2004, p. 11).

Para melhor compreensão dos mecanismos de que dispõem o olhar da verdade e o olhar da mentira, observemos a seguir.

No olhar da verdade, ou seja, naquele onde operam dois olhos sadios, temos um ser vidente e um objeto visto em plena passividade. O olho vê como uma reação natural e biologicamente involuntária do corpo humano. Bastaria se posicionar, de olhos abertos, diante de dada coisa para que ela fosse projetada no intelecto daquele que vê, independentemente de sua vontade. O olhar da mentira, contrariamente, só poderia compreender o objeto por meio de uma atividade criativa, de forma que toda a ação de ver partiria do ser vidente. Logo, a visão proveniente de um olho sadio e outro cego estabeleceria uma relação de reversibilidade entre ser vidente e objeto, tornando homem e mundo igualmente ativos na tarefa de trazer toda a existência à luz.

Há, neste terceiro caso, a visão de um ser que comunga com o objeto em plena reciprocidade. A passagem a seguir comprova que a suposta relação do avô com o mundo, pela visão, não era de passiva contemplação, mas de ativa comunhão. Vale ressaltar que tal teoria acerca do olho de vidro era problematizada somente pelo neto, que supunha as diferentes maneiras de ver do avô a partir de seu ponto de vista.

Meu avô imaginava sempre, eu acreditava. Vencia as horas lerdas deixando o mundo invadi-lo por inteiro. Ele hospedava essa visita sem espanto. (...) O que seu olho de vidro não via ele fantasiava (QUEIRÓS, 2004, p. 6).

Ao acreditar que o avô vivia de fantasias, é o narrador que acaba por assumir a visão de olho de vidro. Pouco se abre espaço, durante a narrativa, para as atividades do 
avô, o que sugere uma figura séria e de poucas palavras. Se o olho de vidro era capaz de ver os invisíveis, era porque assim supunha o neto. Era no silêncio e pelas vias da curiosidade que o menino se ligava ao avô, sem dele obter resposta para suas inquietações. Retomando ideias representadas anteriormente, poderíamos dizer que havia um movimento de percepção unilateral, apenas do neto, em direção ao avô. Uma vez que o diálogo, tanto verbal como vetorial, não era estabelecido, tanto o avô quanto o menino perdiam sua veracidade existencial. Para ser, é preciso ser visto.

Se alguém nos olha, nos multiplica. Passamos a ser dois. (...) Mas no olhar de meu avô eu só podia ser um. E ser dois é ter um companheiro para aventurar, outro irmão para as errâncias (QUEIRÓS, 2004, p. 6-7).

Toda pessoa é gêmea de si mesma. Há sempre um outro escondido dentro de nós que nos vigia em silêncio. Só aqueles que possuem um olhar de vidro não refletem isso. Meu avô me reduzia, me fazia solitário. Eu me sentia único, órfão, sem portas para saídas (QUEIRÓS, 2004, p. 7).

As duas passagens destacadas retomam um princípio da fenomenologia, movimento intelectual que surgiu com Edmund Husserl (1859-1938) como uma nova possibilidade investigativa sobre a ontologia do homem e do mundo. Como seu próprio nome sugere, tal teoria filosófica pressupõe que toda existência é um fenômeno, e, portanto, parte de uma experiência de alteridade viva e latente. Isso é dizer que um indivíduo só o é no presente da experiência em que sua figura se entrelaça àquela de outro indivíduo. Somos o que somos por inerente diferenciação daquilo que deixamos de ser diante do outro. Trata-se de um jogo de diferenciação dupla e reversivelmente fundadora da existência do ser e do outro, de forma que um nada mais é que o prolongamento de seu coexistente. 
Por não ser visto pelo avô, seja devido à cegueira do olho de vidro, seja pela personalidade fria e indiferente às suas investidas afetivas, o neto tornava órfão de si mesmo, uma vez que sua condição dialética de ser não era estabelecida. Para não deixar de ser, o neto então fantasiava que o olho de vidro o via com doçura. "Eu sempre acreditei mais no olho da mentira que no olho da verdade. Com o olho da mentira meu avô só me via com encantos" (QUEIRÓS, 2004, p. 9).

Não só em relação ao outro o ser encontra sua verdade. É também na trama interna onde habitam seus invisíveis que se sustenta o ser visível. O personagem-narrador vê no olho de vidro a possibilidade factual de poder ser observado por si próprio. Afinal, todas as noites o avô deixava o olho de vidro descansar sobre um pires, de forma que este pudesse velar o sono daquele.

Eu também gostaria de possuir um olho assim, que ficasse distante de mim, sobre o criado. Ter meu olho me espiando de longe. Quem sabe, eu me conheceria melhor? Conheceria minha superfície sem precisar de espelho (QUEIRÓS, 2004, p. 13).

A pergunta que o narrador faz demonstra que conhecer a própria superfície, como se estivesse diante de um espelho, não basta para perceber um ser por inteiro.

O olhar de sobrevoo, que compreende um par de olhos sadios, equipara-se à leitura de referenciais que possam ser devidamente decodificados. Dois olhos da verdade atuam sem contradição, limitando a experiência do ser - seja consigo mesmo, com o mundo ou com o texto - a uma dimensão rasa e superficial. Por se tratar de uma atividade passiva, o mundo aparece diante dos olhos sadios como uma verdade imóvel e irrevogável. Como a verdade de um mundo tão vasto caberia em verdades tão pequenas, é o que intrigava o narrador. Ele estranhava: "Verdade é difícil de acreditar. Verdade traz 
dúvidas" (QUEIRÓS, 2004, p. 45). E confessava: "Tenho medo da palavra verdade. É tão crua. Parece feita de faca. A palavra verdade não permite o erro, daí não conhecer o perdão" (QUEIRÓS, 2004, p. 9).

A certeza que busca o olhar sadio não permitiria a um poeta dizer que "queria crescer para passarinho", pois haveria nesta oração um erro semântico. Daí afirmar que é preciso ser poeta para ler poema, é preciso ter olho de vidro para perdoar o erro, acolhêlo e descobrir por debaixo de sua veste vocabular uma verdade palpitante.

A dúvida sempre me salvou. As pessoas que cismam ter encontrado a verdade me assustam. Daí gostar do meu avô. Ele sempre duvidava do que via. E se via, fazia de conta que não via. Ele escolhia o que ver. Quando nos negamos a ver é porque já vimos. E fica impossível desver (QUEIRÓS, 2004, p. 9).

Não seria preciso nascer cego, nem se tornar cego, como aconteceu com o galo de briga do narrador. A atividade do olho de vidro do avô era fantasiada pelo narrador, que por sua vez adotou a suposta visão do avô como sua. Há, no olho de vidro, uma atitude voluntária de se relacionar com o mundo. Da convivência com o avô, o narrador herdou o olho de vidro e, com ele, a sensibilidade de enxergar o mundo por completo.

Mas para mim, depois de passar de mão e mão, restou seu olho de vidro, agora sobre minha mesa, dormindo num pires. E sempre que passo diante dele repito: olho de vidro não chora. Olho de vidro brilha por não ver. Nunca vou saber o que o olho de vidro do meu avô não viu (QUEIRÓS, 2004, p. 46).

A narrativa nasce não só da dúvida do neto sobre o que o avô teria visto durante a vida toda, mas também do que continuou a ver o olhar de vidro herdado pelo neto. Não seria suposição nossa dizer que o olhar do personagem é o que fez do narrador um 
literato. Era sobre o avô que ele dizia: "Seu olhar comprido derramava certa doçura tímida sobre todas as coisas como um olhar de poeta" (QUEIRÓS, 2004, p. 14).

Apesar da característica do olhar ser atribuída ao avô, é o narrador quem desmascara as rasas verdades do mundo pela palavra metafórica que, apesar dos visíveis, vela profundos invisíveis. "Palavra não nasce em árvore, brota no coração. A gente sabe que ela tem cor, porém cada uma guarda uma ilusão" (QUEIRÓS, 2004, p. 35).

A palavra metafórica, ou ainda, a palavra poética característica do texto literário se abriga na metáfora do olho de vidro. Diz o narrador: "Nunca vi cisco incomodar o olho esquerdo do meu avô. É um olho morto e ao mesmo tempo eterno. Ainda hoje ele continua me espiando" (QUEIRÓS, 2004, p.30).

O olho morto, tal qual a palavra morta para significação imediata, abre visão para um misterioso e potente universo. Olho de vidro e palavra poética participam deste que é um processo de transcendência significativa. Ao romper para a experiência perceptual e estético-literária, passa-se a operar num campo de significação atemporal e, portanto, eterno.

A eternidade da experiência perceptual se identifica na Literatura na medida em que ela se atualiza constantemente pela leitura, sendo capaz de despertar no homem sua essência experimentativa e sensorial, levando-o a reconciliar-se com sua infância e, logo, com sua humanidade.

A eternidade do olho de vidro ainda poderia ser atribuída à própria infância que, "sendo um momento da história que se repete eternamente, manifesta, nesse eterno retorno, aquilo que essencialmente permanece como fato humano" (JOBIM E SOUZA, 1994, p. 151). 
Em discurso público já citado no início deste artigo, o escritor Bartolomeu Campos de Queirós reconhece que "tudo na percepção infantil possui uma linguagem: plantas, água, vento, flor, pedra, tudo podia ser escutado" (QUEIRÓS, 2010, p. 34). Permitamo-nos fazer uma única correção: tudo na experiência infantil é capaz de comunicar algo. O que a criança percebe já passa a fazer parte de uma vivência simbólica e de segunda ordem. A linguagem de que fala o autor não é a língua formal e institucionalizada, mas a linguagem que comunica pelos sentidos enquanto experiência sempre atual.

Nesse mesmo discurso, Queirós faz referência ao conceito junguiano de que "nascemos originais e morremos cópias" (QUEIRÓs, 2010, p. 34). A originalidade da infância está no encontro bruto e autêntico que a criança estabelece com o mundo a sua volta. Se morremos cópias, é porque nos afastamos do mundo como experiência perceptual direta para podermos reconhecê-lo como símbolos mentais elaborados, na inércia de uma vida acelerada e prática.

A literatura trabalha com a palavra da mesma forma que a criança se relaciona com o mundo a sua volta. Assim como faz a criança ao experimentar o mundo, o leitor do texto literário apalpa os contornos da palavra e permite que ela fale por si antes de atribuir-Ihe um significado próprio.

Tomando emprestada a metáfora de Queirós (2004), para ler o texto literário é preciso ter apenas um olho bom, para encontrar a palavra, e um olho de vidro, para perdê-la no território da experiência estética, onde prevalecem as sensações.

Sendo assim, poderíamos concluir que $O$ olho de vidro do meu avô não se encaixa em uma mera categoria infantojuvenil, mas que se aplica a um tipo de literatura-criança. Literatura esta desapegada de pré-conceitos e aberta à novidade que se faz permanente. 
O que caracteriza a obra como uma produção infantil está além das especificidades desse gênero em seu caráter classificatório. O infantil se revela no fenômeno literário, remetendo à infância como concepção. Tomando a infância como concepção de uma maneira peculiar de ver e experimentar o mundo, não seria toda a literatura, independentemente de suas ramificações, um todo infantil?

\section{Referências}

JOBIM E SOUZA, Solange. Infância e linguagem: Bakhtin, Vygotsky e Benjamin. Campinas, SP: Papirus, 1994.

MERLEAU-PONTY, Maurice. Os pensadores. São Paulo: Abril Cultural, 1980.

. Fenomenologia da percepção. São Paulo: Martins Fontes, 1994.

. A prosa do mundo. São Paulo: Cosac \& Naify, 2002.

. O olho e o espírito. São Paulo: Cosac \& Naify, 2004a.

. The world of perception. New York: Routledge, 2004b.

. O visível e o invisível. São Paulo: Perspectiva, 2009.

QUEIRÓS, Bartolomeu Campos de. O texto literário nos fala e nos escuta. In: QUEIRÓS, Bartolomeu Campos de; SOUZA, Patrus Ananias de. Emoções em desalinho. Belo Horizonte: Clube de Editoras Mineiras, 2010.

QUEIRÓs, Bartolomeu Campos de. O olho de vidro do meu avô. São Paulo: Moderna, 2004.

Recebido em 11 de fevereiro de 2019.

Aceite em 13 de março de 2019.

\footnotetext{
' Este artigo foi adaptado da dissertação de mestrado defendida pelo autor em 2011.
} 
ii QUEIRÓS, Bartolomeu Campos de. O peixe e o pássaro. Belo Horizonte: Miguilim, 1974. 